\title{
ANNOUNCEMENT
}

\section{"Electronic Copy"}

You will not be surprised that the text for ASTIN Bulletin is prepared by the printer using modern computer technology and not old-fashioned letterpress. The printer and the Editors are now willing to experiment with authors' supplying "copy" for their papers in electronic form, supplied on either 3.5 inch or 5.25 inch diskettes. Initially papers must be prepared using only WordPerfect 5.1.

Authors should in the first instance submit papers as usual in typescript (4 copies) to one of the Editors named on the inside back cover. They should at that time indicate that they wish to submit a final text on diskette. They will receive detailed instructions about how the computer version of the paper should be arranged, appropriate to the particular language they propose to use. These instructions are also available on application to one of the Editors.

When the paper has been finally accepted for publication the author will be asked to send a disk with the final text, along with a paper copy, and this will be used by the printer, who will convert the electronic text to a form suitable for actual printing. It is not intended that the final appearance in $A S T I N$ Bulletin of papers processed in this way will be altered.

This procedure is, at this stage, experimental. The advantage to authors should be that fewer proof corrections are required, but it will not eliminate the need for careful checking of proofs by the authors, particularly to ensure that formulae and tables have been transmitted correctly. If the process proves successful it may be possible to extend the facility to other word-processing languages, but there is no guarantee of this. If is proves unsatisfactory, the Editors reserve the right to revert to conventional methods.

DAVID WiLkie 